\title{
Computerised tomography after recent severe head injury in patients without acute intracranial haematoma
}

\author{
J. S NOEK, BR Y A N JEN NETT, J. HUME A D A M S, \\ D. I. G R A H A , A N D D. DOYLE
}

From the University Departments of Neurosurgery and Neuropathology, Institute of Neurological Sciences, Southern General Hospital, Glasgow

SUMMARY Sixty patients with severe head injury who did not have an acute intracranial haematoma on CAT scanning are reviewed. The scans are correlated with the level of consciousness at the time of scanning and with the outcome six months after injury. The initial scan was interpreted as being normal in $38 \%$ of the cases. In the remainder the most common abnormalities were small ventricles and areas of mixed increased and decreased density interpreted as contusions. All the patients with small ventricles were under 20 years of age. Postmortem examinations were undertaken on 15 of the 19 fatal cases. There was evidence of a high intracranial pressure in 12 , cerebral contusions were absent or minimal in 10, there was diffuse immediate impact damage to white matter in six, and there was moderate or severe hypoxic damage in four.

The most obvious value of CAT scanning after recent head injury is to identify and localise acute intracranial haematomas, and this it does with a high degree of accuracy (Galbraith et al., 1977). But even in neurosurgical units which operate a selective admission policy, only a proportion of the patients referred have a haematoma, and the management of other patients who are in coma remains a difficult problem.

We review here the CAT scans of 60 patients with a severe head injury who did not have an acute intracranial haematoma. Scans are correlated with the level of consciousness at the time of scanning, with the outcome six months after injury and, in those who died, with the neuropathological findings.

\section{Patients and methods}

The patients had all sustained non-missile injuries, over $80 \%$ being the result of road accidents. Males were five times more common than females, and $68 \%$ of the patients were younger than 20 years.

\footnotetext{
Address for correspondence and reprint requests: Professor Bryan Jennett, Department of Neurosurgery, Institute of Neurological Sciences, Southern General Hospital, Glasgow G51 4TF.

Accepted 3 October 1978
}

A fractured skull was found in $42 \%$ and hemiparesis in $53 \%$. All of the patients were admitted to the regional neurosurgical unit in Glasgow, to which patients are referred from the primary surgical wards of other hospitals, because they are considered to need special investigation or treatment. All patients were severely injured by the criterion of the international collaborative study (Jennett et al., 1977b)-that is, they were in coma for at least six hours, coma being defined as the inability to obey commands, to utter words, or to open the eyes. Only two-thirds had their first scan within 24 hours of injury, and by the time the first scan was done, $42 \%$ of the patients were out of coma by this definition.

In 10 patients angiography was performed before a scan was done, usually because the scanner was not immediately available, and an urgent investigation was considered necessary; these angiograms were all normal. General anaesthesia was employed in $60 \%$ of the patients in order to ensure scans of good diagnostic quality; inthree patients, however, the quality of the scans was suboptimal but was regarded as sufficient to exclude a significant intracranial haematoma. Patients whose scan showed any evidence of an extracerebral collection of blood or the presence of a circumscribed 
intracerebral haematoma were excluded from the present series, even when surgery was not considered necessary. The remaining abnormalities were classified into five categories: (i) lateral shift of the ventricles; (ii) a compressed ventricular system, suggestive of diffuse swelling of the brain; (iii) localised areas of reduced density, interpreted as "oedema" or as infarction; (iv) areas of mixed increased and decreased density, interpreted as contusions; (v) other abnormalities, most of ten evidence of blood in the ventricles or in the Sylvian fissures.

The outcome six months after injury was classified according to a scale previously described (Jennett and Bond, 1975). There were 19 deaths, and in 15 of these necropsy and detailed neuropathological examination were carried out.

\section{Results}

The initial scan, although not disclosing a haematoma, was abnormal in $62 \%$ of the 60 patients. Some patients had more than one abnormality (Table 1). More than a third of the abnormal scans showed narrowing of the ventricles, sometimes to the point of being scarcely discernible; when the ventricular system could be visualised in these cases there was no shift. The brain parenchyma was either normal or showed homogeneously reduced density in such cases, and these patients were all young, seven being 5 , seven aged $5-13$, and one aged 17 years. Areas of mixed reduced and increased density were the most common other findings, and in some cases these were associated with lateral shift. Abnormal scans were found somewhat more often in patients who were still in coma or who had a skull fracture but were less common in patients with hemiparesis than in those without (Table 2).

Repeat scans could not be performed routinely because of limited availability of the scanner, but they were done in 15 patients. In four cases the scan was initially abnormal but was normal when repeated at $1,2,15$, and 27 days. In seven cases

Table 1 Frequency distribution of 41 scan abnormalities in 37 patients

\begin{tabular}{lll}
\hline Abnormality & Patients & \\
\cline { 2 - 3 } & Number & 37 \\
\hline Small ventricles & 15 & 20 \\
*Mixed density change & 8 & 14 \\
Lateral shift only & 6 & 12 \\
*Local reduced density & 5 & 17 \\
Other findings & 7 & \\
\hline
\end{tabular}

*In each of these categories two patients had lateral shift also.
Table 2 Incidence of abnormal CAT scans soon after head injury

\begin{tabular}{|c|c|c|c|}
\hline \multirow[t]{2}{*}{ Status of patient } & \multirow{2}{*}{$\begin{array}{l}\text { Number of } \\
\text { patients }\end{array}$} & \multirow{2}{*}{$\frac{\text { Abnormal }}{\text { Number }}$} & \multirow[b]{2}{*}{$"$} \\
\hline & & & \\
\hline Out of coma & 25 & 13 & 52 \\
\hline Still in coma & 35 & 24 & 69 \\
\hline No skull fracture & 34 & 18 & 53 \\
\hline Skull fracture & 26 & 19 & 73 \\
\hline No hemiparesis & 28 & 19 & 70 \\
\hline Hemiparesis & 32 & 18 & 56 \\
\hline $\begin{array}{l}\text { No hemiparesis } ; \text { no } \\
\text { skull fracture } \\
\text { Hemiparesis }: \text { skull }\end{array}$ & 18 & 11 & 61 \\
\hline fracture & 16 & 10 & 63 \\
\hline
\end{tabular}

None of the differences in incidence between pairs is significant at 0.05 .

the repeat scan showed continuing abnormality. In four patients whose initial scan was normal, it was still normal when done again. During the study there were two patients in whom a large intracerebral haematoma was found on repeat scan; in one of these the initial scan on the previous day had shown only a small area of contusion (Fig. 1), while in the other case the initial scan also the day previously, had been considered $\overrightarrow{0}$ normal. Both of these patients had deterioratec dramatically and it was this which had led to the scan being repeated. Both died in spite of surgicate intervention. Because they had intracranial hae 8 matomas, albeit only on their second scan, the are not included in the present analysis.

The outcome distribution six months after in? jury was similar in this series of patients to that found in the international collaborative head injury study for patients without intracranial haematoma (Table 3). The outcome was much better for patients who had emerged from coma by the time their scan was done, but it was only marginally better for those with a normal as distinct from an abnormal CAT scan (Table 4). An abnormal CAT scan did not appear to influence the outcome either in patients already out of or in those still in coma. Of 15 patients with compressed ventricles, eight survived and became independent. The necropsy findings in those who died are discussed below.

\section{NEUROPATHOLOGY (Table 5)}

Postmortem examinations were undertaken in 15 of the 19 fatal cases. The brains were fixed intact, and then subjected to a comprehensive neurohistological analysis (Adams et al., 1977). These 15 cases did not differ significantly from the rest of the series in respect of age, frequency of skull fracture, or incidence of abnormal scans. The age 

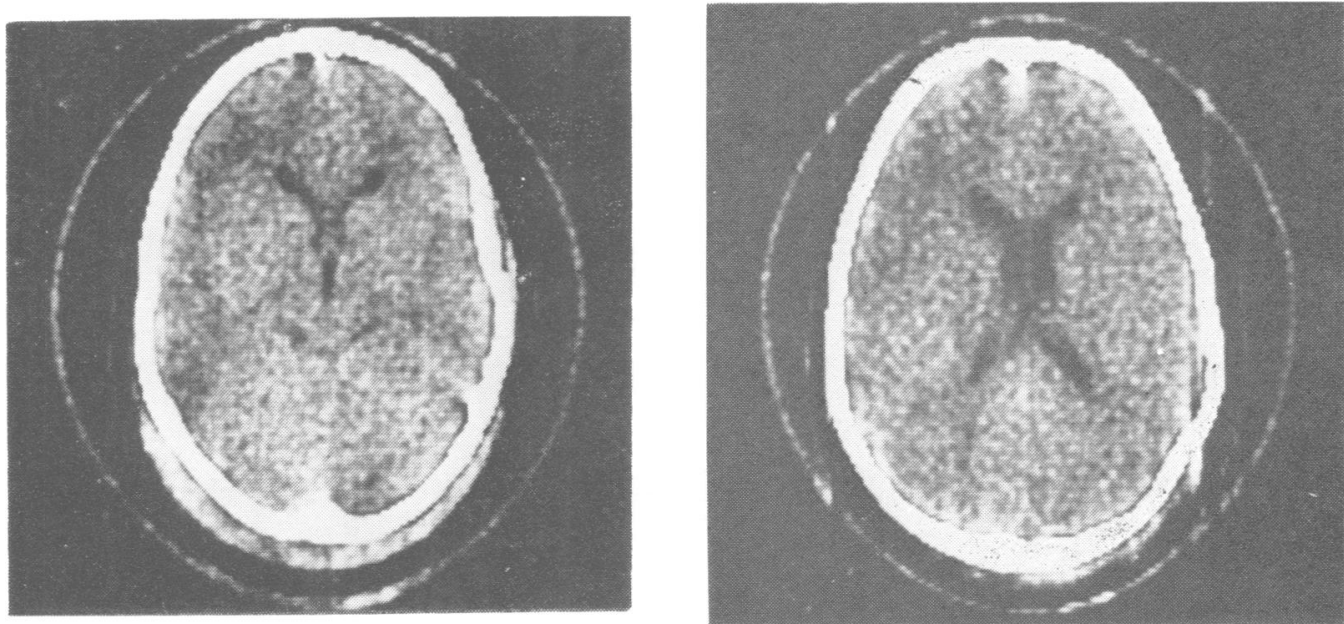

(a)
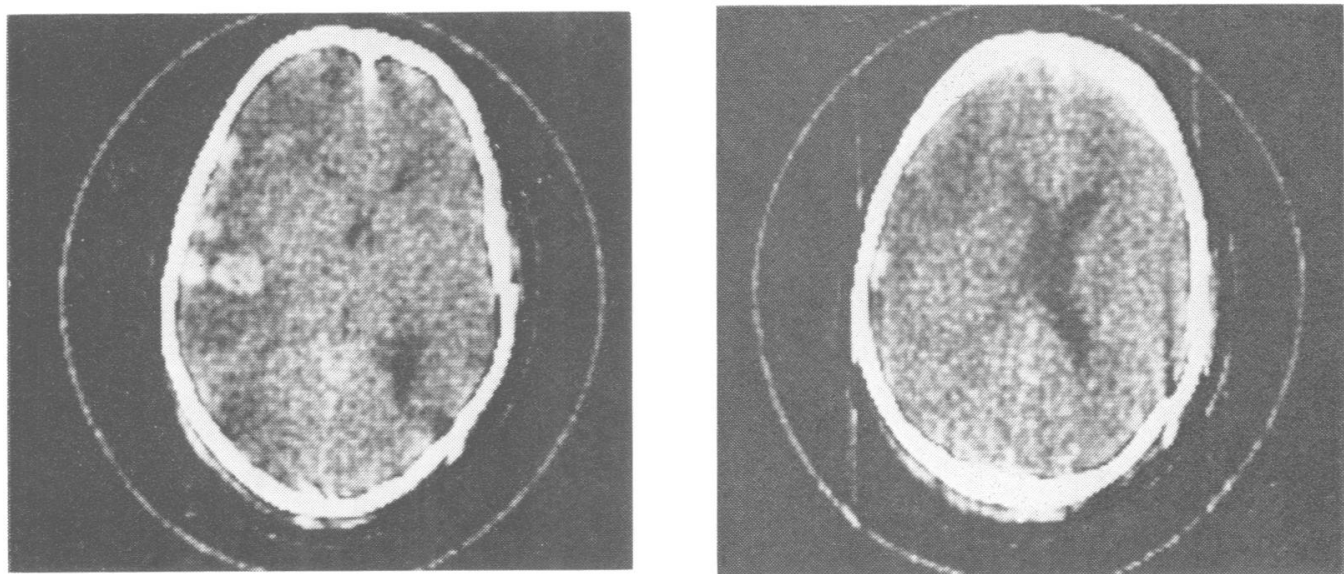

(b)

Fig. 1 (a) CAT scan two and a half hours after injury. There is no shift of the ventricles. An area of mixed reduced and increased density in the left frontoparietal area is suggestive of contusion. (b) CAT scan 24 hours after injury. There is now marked displacement of the ventricles to the right, contusions are obvious and these amount to an intracerebral haematoma in the left posterior frontal region. JMcS, aged 5 years. Fell out of a fourth floor window. He was unconscious on admission, reacting to painful stimuli by abnormal flexion of limbs. Radiography revealed a right parieto-occipital fracture. The patient's condition improved to the state where he was localising to pain, but the next day he started having apnoeic attacks. After the repeat CAT scan, craniotomy revealed a left frontal intracerebral haematoma, and a left frontal lobectomy was performed. No material improvement after operation, died four days after the accident.

Table 3 Outcome of severe head injuries

\begin{tabular}{lllll}
\hline & $\begin{array}{l}\text { Number of } \\
\text { patients }\end{array}$ & $\begin{array}{l}\text { Severe } \\
\text { Dead } \\
(\%)\end{array}$ & $\begin{array}{l}\text { Modsability } \\
(\%)\end{array}$ & $\begin{array}{l}\text { Good recovery } \\
(\%)\end{array}$ \\
\hline $\begin{array}{l}\text { Scan series } \\
\begin{array}{l}\text { Cases in } \\
\text { data bank } \\
\text { without } \\
\text { haematoma }\end{array}\end{array}$ & 60 & 32 & 8 & 60 \\
\hline
\end{tabular}

None of the differences between series is significant at 0.05 .
Table 4 Mortality of severe head injuries without haematoma

\begin{tabular}{lllrrr}
\hline & $\begin{array}{l}\text { Number of } \\
\text { patients }\end{array}$ & Norinal CAT scan & Abnormal CAT scan \\
\hline All cases & 60 & $5 / 23$ & $22 \%$ & $14 / 37$ & $38 \%$ \\
Out of coma & 25 & $0 / 12$ & $0 \%$ & $0 / 13$ & $0 \%$ \\
Still in coma & 35 & $5 / 11$ & $45 \%$ & $14 / 24$ & $59 \%$
\end{tabular}

Differences in mortality between normal and abnormal scan series are not significant at 0.05 . 


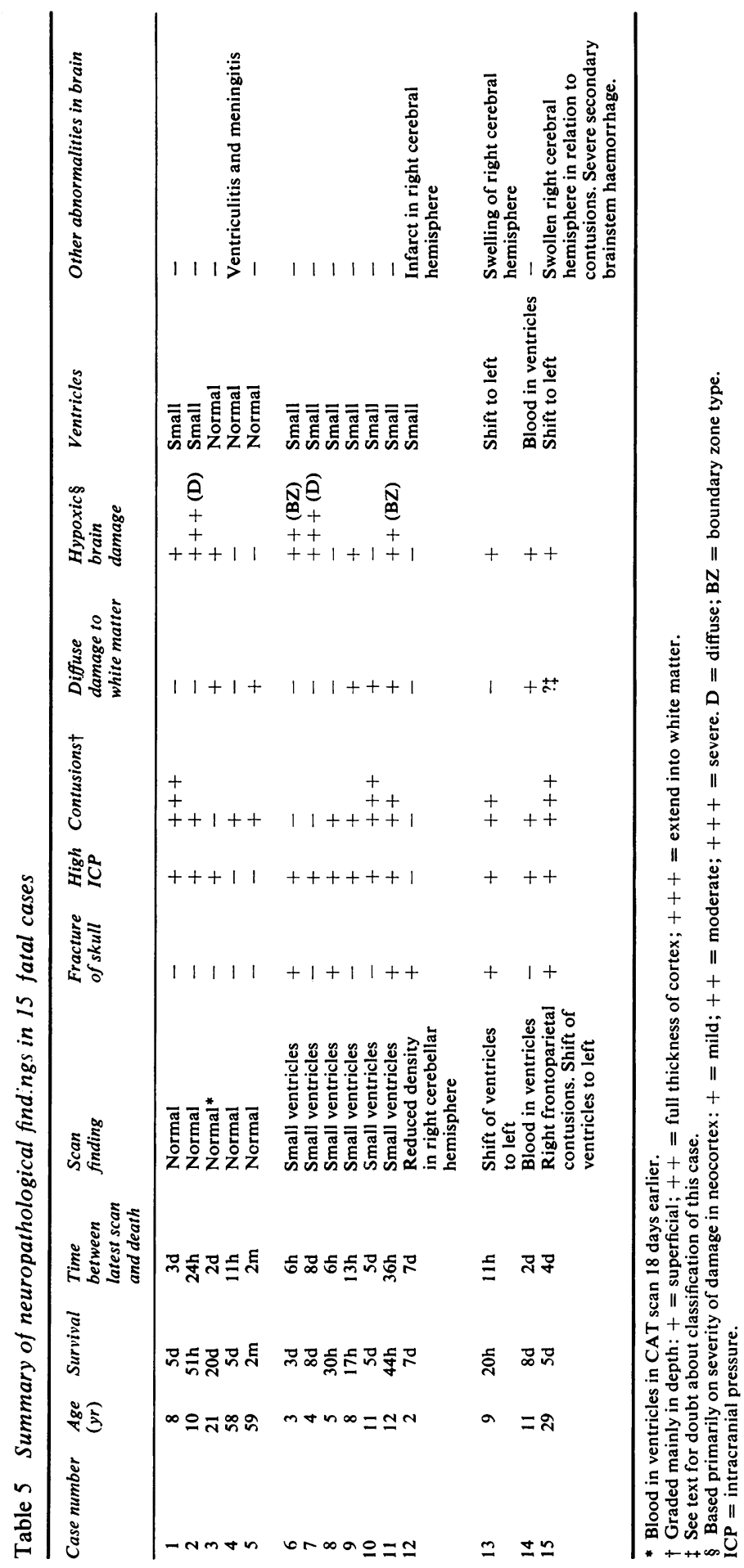


range was from 2 to 59 years, and 11 were children aged 12 years or less. Survival ranged from 17 hours to two months after injury. Thirteen of the patients had been unconscious from the moment of injury until death. The two who "talked" (Reilly et al., 1975) were cases 2 and 4 (Table 5) where the principal neuropathological findings were intracranial infection and severe hypoxic brain damage respectively.

Cerebral contusions were absent in four cases, minimal (restricted to the outer layers of the cortex) in six, moderate (affecting the full thickness of the cortex) in two, and severe (extending into the white matter) in three (Fig. 2).

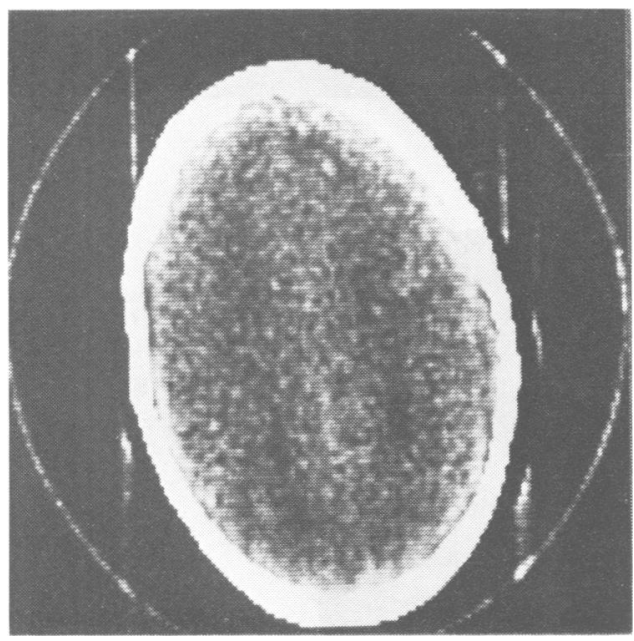

(a)
Diffuse damage to white matter of immediate impact type (Adams et al., 1977) was identified in six cases (Figs. 3, 4). None of these patients had talked at any time after their injury, and not one had a fracture of the skull. Contusions were absent or minimal in four, and moderate or severe in two. There was probably a seventh patient (case 15 , Table 5) with diffuse damage to white matter but this could not be confirmed beyond doubt because of the presence of severe secondary brainstem damage.

Hypoxic damage in the cerebral cortex of the type we have defined elsewhere (Graham et al., 1978) was identified in 10 cases. This was severe

Fig. 2 (a) CAT scan 48 hours after injury, interpreted as showing no definite abnormality. (b) Pathology: there are severe haemorrhagic contusions extending into the white matter at the right frontal pole. Case 1 $(M M c N)$ aged 8 years. Pedestrian road accident (mentally defective). Deeply unconscious, pupils reacting, no focal signs, no skull fracture, no other injuries. Died on the fifth day.

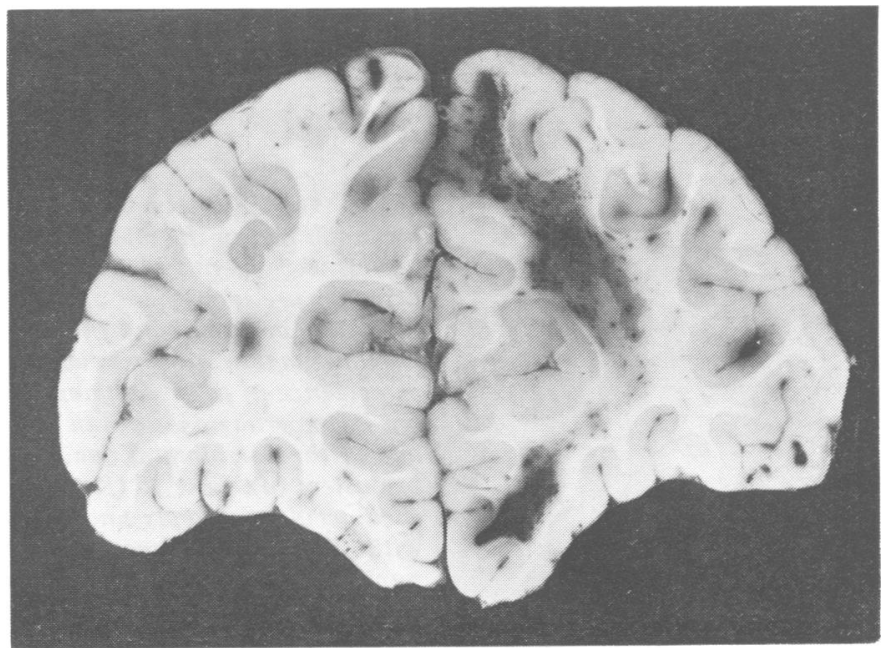

(b) 
(a)

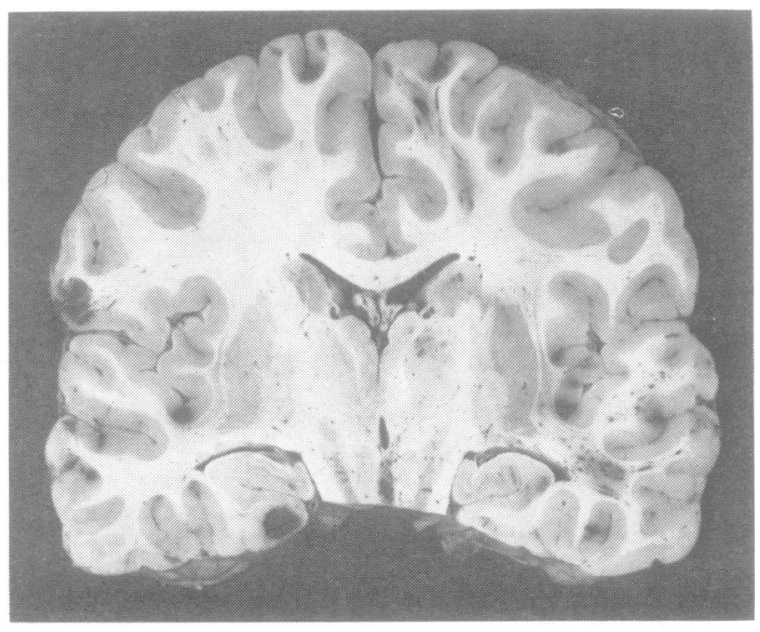

(b)



(c)

Fig. 3 (a) CAT scan on day of injury. The ventricle. are small and in the midline, and no parenchymal


lesions were identified at any level. The laterally placed densities are movement artefacts. Pathology: the ventricles are small and there are numerous haemorrhagic contusions in the cortex (b) and (c); as evidence of diffuse damage to white matter, there are haemorrhagic lesions in the corpus callosum (c) and in the dorsolateral quadrant of the rostral brainstem $(d)$. Case $10(K A)$ aged 11 years. Pedestrian road accident. Deeply unconscious from beginning with extensor motor responses in the limbs, unequal pupils, no skull fracture. Fractured femur and pubic ramis; also silent, rigid abdomen which yielded blood on peritoneal lavage but no ruptured viscus on laparotomy. Died five days after injury. 


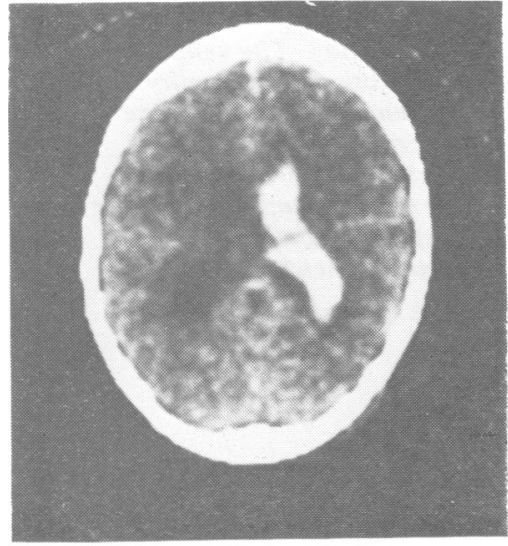

(a)



(c)

and diffuse in two, and moderately severe and of boundary zone type in two. One of the two latter cases had been severely hypotensive on admission to hospital.

Neuropathological evidence of a high intracranial pressure, using the criteria we have already defined (Adams and Graham, 1976) was found in 12 of the 15 cases despite the absence of any case with an acute intracranial haematoma.

The ventricles were small in all of the cases in whom the CAT scan had shown compressed ventricles (Table 5, cases 6-11). Three of these cases had diffuse damage to white matter (Fig. 3), in two there was moderate or severe hypoxic brain damage, while the sixth (case 8 ) could only be classified as an example of "idiopathic brain

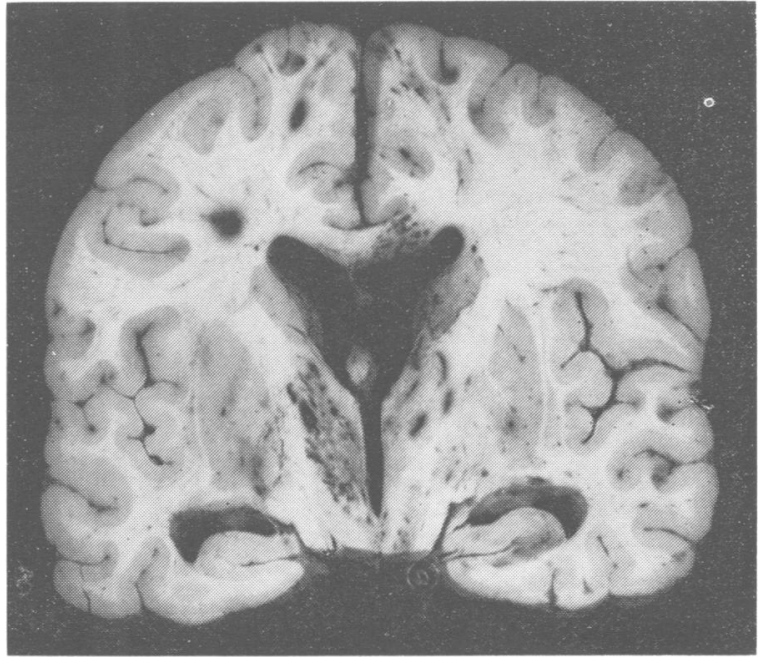

(b)

Fig. 4 (a) CAT scan on day of injury. There is an almost complete blood cast of the right lateral ventricle. No parenchymal brain lesion detected. Pathology: there is a large haemorrhagic lesion in the corpus callosum (b) and there was blood in the ventricles; there is also a large haemorrhagic lesion in the dorsolateral quadrant of the rostral brainstem (c). Case $14(A M)$ aged 11 years. Pedestrian road accident. Deeply unconscious with extensor motor responses in the limbs, pupils reacting, no skull fracture; only other injury was a fractured clavicle. Died on eighth day.

swelling" (Fig. 5), a well-recognised entity in children (Lindenberg et al., 1955; Adams, 1975).

CORRELATION BETWEEN CAT SCAN AND

NEUROPATHOLOGICAL FINDINGS

Two factors limit the comparison of scans with pathological findings. One is the interval between scanning and necropsy, the other the difficulty of matching scan cuts with brain slices. Fixed brains can be sliced in approximately the same planes as the CAT scans but since so much vital information is impossible to identify in such slices, we have adhered to conventional coronal sections in order to maintain continuity in our pathological studies on head injuries over many years.

The most striking feature was the severity of the 


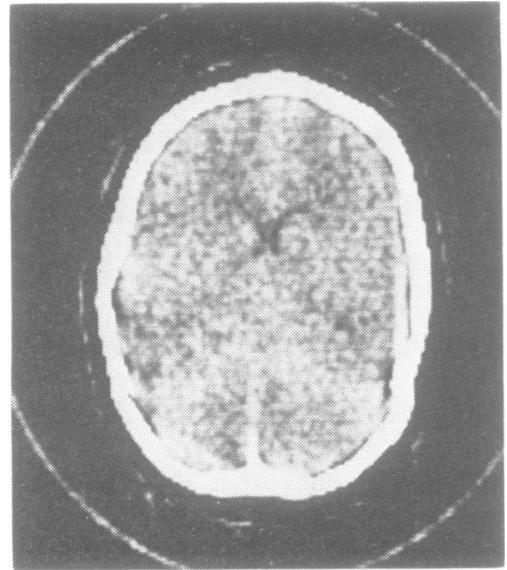

Fig. 5 (a) CAT scan on day of injury. The ventricles are small and in the midline, no other abnormality identified. (b) Pathology: the ventricles are small and there are bilateral tentorial herniae (arrows). Case 8 $(T M c P)$ aged 5 years. Pedestrian road accident. In coma from beginning, pupils reacting and limbs flexing at first; limbs became less responsive and pupils fixed after 20 hours. Fractured femur, clavicle, mandible, and skull. Died at 30 hours.

(a)

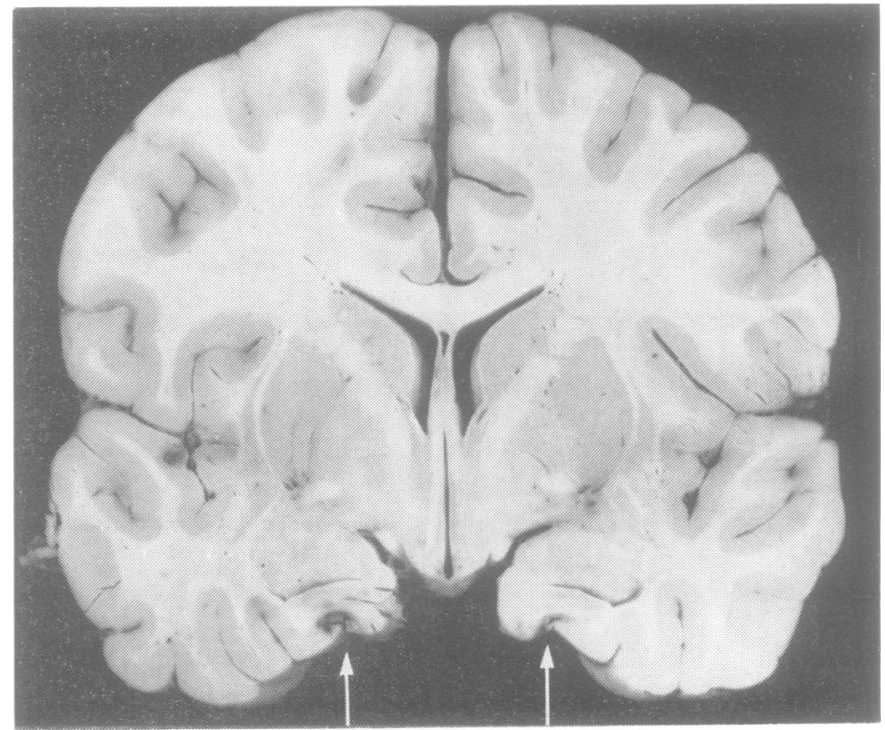

(b)

brain damage found in the five cases with normal scans and in the six with small ventricles. No parenchymal lesion was detected in the scans of the six patients with severe impact damage to white matter, but two had blood in the ventricles soon after injury (Fig. 4). It is likely that the lesions in the corpus callosum and in the dorsolateral quadrant of the rostral brainstem, which are such a consistent pathological finding in such cases, might be shown up in scans if a tomographic cut happened to be at the right level. But we did not see such lesions on any of the six scans from the patients with this type of brain damage, nor in another who had a particularly large lesion in the corpus callosum. This case was not included in the present analysis because she was seen only in consultation a month after injury when she was in a vegetative state. A scan then showed only some ventricular dilatation, but at necropsy the classical lesions of diffuse white matter damage were seen (Fig. 6).

In two of the three cases which were found postmortem to have severe contusions-that is, contusions extending through the full thickness of the cortex into the white matter (Fig. 2)-the contusions had not been identified in the CAT scans. None of the less severe contusions was seen in the CAT scans. 


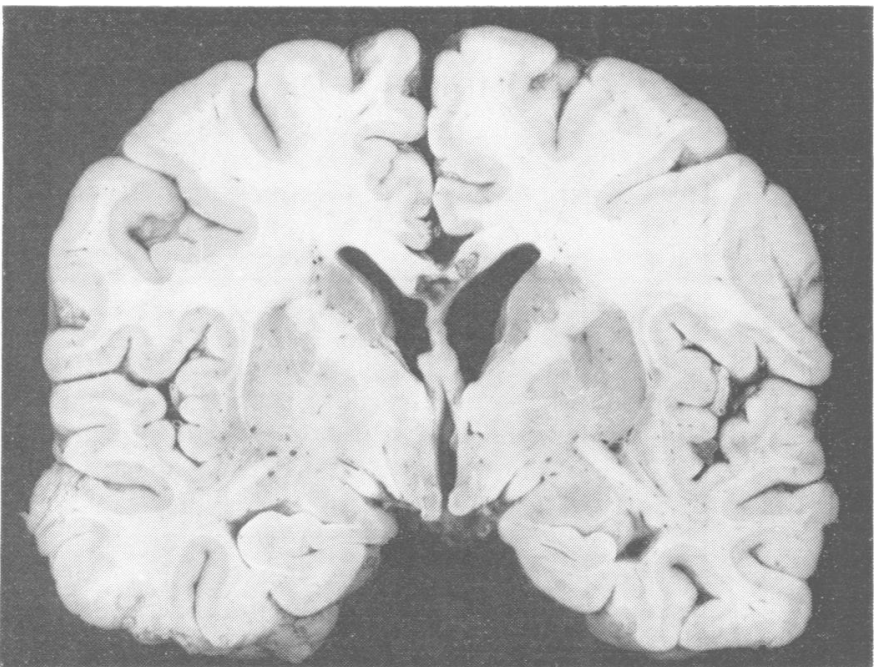

Fig. $6 C A T$ scan four weeks after injury showed some ventricular dilatation but no parenchymal abnormality in cerebral or posterior fossa cuts. Pathology: there is a large organising and partly cystic lesion in the corpus callosum which was not identified in the CAT scan. $M M c V$, aged 16 years (not in consecutive series). Fell down lift shaft. Deeply unconscious: with extensor limb responses, no skull fracture. Haemopneumothorax, ruptured right kidney, lacerated liver and ovary. Blood pressure 90/60 $\mathrm{mmHg}$ before resuscitation and laparotomy. Mechanical ventilation (tracheostomy) for four weeks, by which time she was in a vegetative state and had developed a series of epileptic fits. Died three months after injury.

There was no case in the series in which an intracranial haematoma was disclosed after death. The two cases which developed delayed intracerebral haematomas, which were detected on repeat scanning (Fig. 1) and operated on, both died. At necropsy after such surgery it is not easy to determine what the previous state of the brain had been, but we concluded that each of these patients had had significant contusions.

The pathological lesions which are typical of raised intracranial pressure, of diffuse white matter damage, and of recent hypoxic brain damage are either small or only recognisable at microscopic level, and it is therefore, not surprising that they are not evident on CAT scanning. Their presence may be suspected from circumstantial evidence, both clinical and from the scan. But it is clear that caution is called for in drawing conclusions from the scan alone, particularly in the direction of regarding a normal or near normal scan as excluding severe brain damage.

\section{Discussion}

The value of CAT scanning in the recognition and localisation of intracranial haematoma is undeniable (Galbraith et al., 1977). How much scanning can help in the diagnosis and prognosis of other traumatic lesions has still to be defined. However, it is already clear that it makes it possible to detect during life the presence of some pathological lesions which could previously only be suspected until necropsy. These include contusions, oedema, infarction, and intraventricular blood. Moreover, serial scanning enables the evolution and resolution of these lesions to be visualised. which was previously impossible.

One of the earliest reports of head injuries examined by CAT scanning was from Boston (Merino-de Villasante and Taveras, 1976). This stated that abnormalities on scanning increased proportionately with clinical severity. All patients with injuries "more severe than contusion" had abnormal scans but the authors admitted that their classification of clinical severity lacked "a very precise characterisation of each group." A larger and more representative series was reported the following year from Sacramento (French and Dublin, 1977). While the more severely injured more often had abnormal scans, no less than $44 \%$ of those with "deep coma and abnormal motor movements" had a normal scan, as did $15 \%$ of those in coma with lateralising signs.

Our experience is much closer to that of Sacramento than that of Boston. All the Glasgow patients were in coma by a rigorous definition, and yet $38 \%$ had normal scans; $26 \%$ of fatal cases had no definite CAT abnormality. In this series only four patients had contrast enhancement because this was not considered likely to contribute to management in the acute stage after injury. It may be argued that some scans which were regarded as normal might have shown abnormalities if more extensive and careful examination had been carried out, with more brain slices, including posterior fossa cuts, and contrast enhancement in every case. Certainly more subtle abnormalities may be revealed by careful retrospective review, including evidence available from serial scans over several weeks, as recently reported by Zimmerman et al. (1978a). But head injuries present urgent problems, often at night, and not only the scan- 
ning but also the interpretation must of ten depend on junior radiographic and medical staff, without the benefit of an experienced radiologist. It is in these circumstances that clinicians need to know what conclusions to draw when a scan is normal, or when various abnormalities are seen which are less obvious and less easy to interpret than a haematoma.

The neuropathological findings in the 15 cases in this series exemplified the type of brain damage one would expect to find in fatal cases without an intracranial haematoma, on the basis of a study of a large number of consecutive headinjured brains already analysed and reported (Adams, 1975). Thus many did not have a fracture of the skull, and the postmortem examination frequently revealed neither severe contusions nor lacerations of the brain. There were six casespossibly seven-with severe diffuse damage to the white matter of immediate impact type, and four with moderate or severe hypoxic brain damage. There were two cases with swelling of one cerebral hemisphere in relation to contusions, and one with idiopathic post-traumatic brain swelling.

Although this study confirms the reliability of CAT scanning in excluding an intracranial haematoma it cannot yet be claimed that there are characteristic scan appearances for various other types of traumatic brain damage. Indeed the CAT scan may be normal even when severe and irreversible brain damage has occurred, and a normal scan cannot, therefore, be equated with a good prognosis. If, however, the scan is interpreted in the context of the clinical picture it may be possible to derive useful data from a normal or near normal scan, other than the exclusion of gross lesions.

The group of patients with small, undisplaced ventricles is particularly interesting. It was the most frequent single abnormality, and on reviewing the scans of other patients which had been reported as normal there were some which had relatively small ventricles. There are as yet no clearly defined criteria for the range of size in normal individuals at various ages, and caution is needed in interpreting this finding until more data are available and methods of measuring ventricular size and establishing the normal range have been evolved. Six cases with small ventricles on scanning came to necropsy; only one had severe contusions while all had marked swelling of the white matter. Other findings in such cases were diffuse impact damage of white matter, and severe hypoxic brain damage. Bruce et al. (1978) reported small ventricles in one-third of their series of severe head injuries in children. In the present series 14 out of 15 patients with this finding were under 14 years of age, and the exception was only 17 years old. Bruce and his colleagues postulated that this appearance was often the result of cerebrovascular dilatation, on the grounds that the brain parenchyma showed increased density and that in cases where blood flow was measured it was increased. Our findings, however, indicate that this CAT scan appearance can be associated with a variety of pathological lesions.

Only two patients whose initial scans did not show an intracranial haematoma subsequenily developed this complication; each showed marked clinical deterioration which led to the repeat scan (Fig. 1). When all patients in coma on admission were routinely scanned in one American series (Sweet et al., 1979) almost all significant intracranial haematomas were found to be already visible on the scan done soon after admission. Nevertheless our two cases emphasise that the absence of a haematoma on an early scan does not exclude its later development. This could be a matter of some importance if large numbers of patients were to be scanned soon after injury as a means of deciding whether complications were likely to develop. How many later developing lesions would have been revealed if repeated scanning had been routine is at present not known. No doubt some lesions which were not of clinical significance might have been found, as we have previously reported (Jennett et al., 1977a), but no significant expanding lesions were found at necropsy which had not been diagnosed on at least one scan. When pursuing a policy of repeated scanning French and Dublin (1977) encountered several focal collections, particularly subdural hygromas, some time after injury. When such lesions have not caused obvious clinical deterioration their significance is doubtful. Their removal did not produce dramatic improvement in any of the Sacramento cases.

Computerised tomographic scanning provides more data about recently head-injured patients than any other investigation, and the only hazard to the patient comes from the use of sedation or anaesthesia, which is sometimes necessary if good quality scans are to be obtained in unco-operative patients. Its most useful role still appears to be the detection of intracranial haematoma. This study shows that a normal scan, or one which shows small but undisplaced ventricles, does not exclude severe impact damage to white matter, extensive secondary hypoxic brain damage, or raised intracranial pressure. Moreover, patients with marked focal signs (hemiparesis) not infrequently have a normal scan. This has also been the experience of others. Lanksch et al. (1978), reviewing 910 recently 
head-injured patients, emphasised that unconscious patients with marked morphological lesions could have normal scans. They concluded that "utilising only CAT findings it is neither possible to predict the patient's outcome nor to decide whether to intervene neurosurgically." Zimmerman et al. (1978b) have reported that the small haemorrhagic lesions, which are commonly associated with diffuse white matter damage of impact type, can often be seen on the scan if examinations are repeated with thin cuts. However, even with careful retrospective review, including serial scans, they found a normal scan in $30 \%$ of patients without haematoma who had impaired consciousness (Zimmerman et al., 1978a).

Until more experience is available, with careful comparison between CAT scans and what is found in the brain at operation or at necropsy, it must remain uncertain what significance attaches to certain findings-and particularly to a normal or near normal scan. The contribution of the scan to prognosis as distinct from diagnosis, may be limited to patients with certain combinations of clinical features and scan appearances. As with other laboratory investigations CAT scans will be most useful only when they are intelligently interpreted in the light of the whole clinical picture.

Dr K. W. Grossart and Dr Peter Macpherson, consultant neuroradiologists, kindly gave us access to the EMI scans, and the consultants of the Department of Neurosurgery in the Institute of Neurological Sciences allowed us to report on cases under their care. We are also grateful to the forensic pathologists in Glasgow for allowing us access to their material.

\section{References}

Adams, J. H. (1975). The neuropathology of head injuries. In Handbook of Clinical Neurology, vol. 23: Injuries of the Brain and Skull, Part I, pp. 35-65. Edited by P. J. Vinken and G. W. Bruyn. North-Holland Publishing Company: Amsterdam.

Adams, J. H., and Graham, D. I. (1976). The relationship between ventricular fluid pressure and the neuropathology of raised intracranial pressure. Neuropathology and Applied Neurobiology, 2, 323332.

Adams, J. H., Mitchell, D. E., Graham, D. I., and Doyle, D. (1977). Diffuse brain damage of immediate impact type. Its relationship to "primary brain stem damage" in head injury. Brain, 100, 489502.

Bruce, D. A., Schut, L., Bruno, L. A., Wood, J. H., and Sutton, L .N. (1978). Outcome following severe head injuries in children. Journal of Neurosurgery, $48,679-688$.
French, B. N., and Dublin, A. B. (1977). The value of computerized tomography in 1000 consecutive head injuries. Surgical Neurology, 7, 171-183.

Galbraith, S., Teasdale, G., and Blaiklock, C. (1977). EMI scanner diagnosis of acute traumatic intracranial haematoma-reliability of a neurosurgeon's interpretations. British Medical Journal, 2, 13711373.

Graham, D. I., Adams, J. H., and Doyle, D. (1978). Ischaemic brain damage in fatal non-missile head injuries. Journal of the Neurological Sciences, 39. In press.

Jennett, B., and Bond, M. (1975). Assessment of outcome after severe brain damage. Lancet, 1, 480484.

Jennett, B., Teasdale, G., Galbraith, S., and Steven, L. (1977a). The role of the EMI scan in the diagnosis and management of traumatic intracranial haematoma. In Computerised Axial Tomography in Clinical Practice, pp. 62-66. Edited by G. du Boulay and I. F. Moseley. Springer Verlag: Berlin.

Jennett, B., Teasdale, G., Galbraith, S., Pickard, J., Grant, H., Braakman, R., Avezaat, C., Maas, A., Minderhound, J,. Vecht, C. J., Heiden, J., Small, R., Caton, W., and Kurze, T. (1977b). Severe head injuries in three countries. Journal of Neurology, Neurosurgery, and Psychiatry, 40, 291-298.

Lanksch, W., Grumme, T., and Kazner, E. (1978). Correlations between clinical symptoms and computerized tomography findings in closed head injuries. In Advances in Neurosurgery, vol. 5: Head injuries-Tumours of the Cerebellar Region, pp. 2729. Edited by R. A. Frowein, O. Wilcke, A. KarimiNejad, M. Brock, and M. Klinger. Springer-Verlag: Berlin.

Lindenberg, R., Fisher, R. S., Durlacher, S. H., Lovitt, W. V., and Freytag, E. (1955). The pathology of the brain in blunt head injuries of infants and children. Proceedings of the Second International Congress of Neuropathology, Part II, pp. 477-479. Excerpta Medica: Amsterdam.

Merino-de Villasante, J., and Taveras, J. M. (1976). Computerized tomography (CT) in acute head trauma. American Journal of Roentgenology, 126, 765-778.

Reilly, P. L., Adams, J. H., Graham, D. I., and Jennett, B. (1975). Patients with head injury who talk and die. Lancet, 2, 375.

Sweet, M. D., Miller, J. D., Lipper, M., Kishore, P. R. S., and Becker, D. P. (1979). Significance of bilateral abnormalities on the CT scan in patients with severe head injury. Journal of Neurosurgery, 50. In press.

Zimmerman, R. A., Bilaniuk, L. T., Gennarelli, T., Bruce, D., Dolinskas, C., and Uzzell, Barbara. (1978a). Cranial computed tomography in diagnosis and management of acute head trauma. American Journal of Roentgenology, 131, 27-34.

Zimmerman, R. A., Bilaniuk, L. T., and Gennarelli, T. (1978b). Computed tomography of shearing injuries of the cerebral white matter. Radiology, 127, 393-396. 